\title{
Competência em Informação na Área da Saúde ${ }^{1}$
}

\author{
Information competence in the health area
}

\begin{abstract}
Lídia Eugenia Cavalcante
Pós-doutora em Ciência da Informação pela Université de Montréal. Professora do Departamento de Ciências da Informação da Universidade Federal do Ceará - UFC. E-mail: lidia@ufc.br

Rosane Maria Costa

Bibliotecária da Biblioteca de Ciências da Saúde da Universidade Federal do Ceará - UFC. Especialista em Tecnologias Aplicadas ao Gerenciamento da Informação.

E-mail: rosanemariacosta@gmail.com

Raimundo Cézar Campos do Nascimento Mestre em Políticas Públicas e Gestão da Educação Superior.

E-mail: rcezarufc@yahoo.com.br

Raquel Jenyffer Souza Santos Graduanda do curso de Biblioteconomia da Universidade Federal do Ceará - UFC. Bolsista de iniciação científica FUNCAP E-mail: jenyffer_ratsu@hotmail.com
\end{abstract}

\section{Resumo}

Apresenta os resultados da pesquisa sobre competência informacional dos estudantes da área da saúde, na Universidade Federal do Ceará, objetivando analisar o comportamento informacional desse público e como compreendem o acesso à informação mediada por computador no âmbito da saúde para a realização de pesquisa científica e produção de trabalhos acadêmicos. O estudo foi realizado mediante a aplicação de questionário para o referido grupo focal. Os resultados evidenciam que os participantes possuem bons conhecimentos no uso das ferramentas tecnológicas e internet, porém demonstram dificuldades em relação ao uso dos repositórios e das fontes especializadas de informação em saúde. Pode-se concluir que se faz necessária a implantação de políticas e programas de competência em informação na Biblioteca de Ciências da Saúde (BCS/UFC), de modo a ampliar o nível de compreensão e uso competente da informação para a produção do conhecimento em saúde.

Palavras-chave: Competência informacional. Acesso à informação. Pesquisa documentária em saúde.

\begin{abstract}
The study presents the results of the assessment on information literacy of health students in the Federal University of Ceará. This research aims to analyze the informational behavior of this group, and how they include access to computer-mediated information in health to carry out scientific research and production of academic work. The data was collected through a questionnaire applied to the group mentioned. The results show that the participants have good knowledge in the use of technological tools and the Internet, but they demonstrate difficulties in the use of repositories and sources of specialized information. The study concluded that it is necessary for to the librarians from the Library of Health Sciences to implement policies and programs of information literacy in order to increase the level of understanding and competent use of information for the production of health knowledge.
\end{abstract}

Keywords: Information literacy. Access to information. Documentary research in health.

\footnotetext{
${ }^{1}$ Artigo apresentado em sua versão original no XII Encontro Nacional de Pesquisa em Ciência da Informação, 2011.
}

InCID: R. Ci. Inf. e Doc., Ribeirão Preto, v. 3, n.1, p. 87-104, jan./jun. 2012. 


\section{Introdução}

O tema competência, em seu sentido amplo, tem efetivamente se tornado um dos assuntos mais discutidos em diversas áreas do conhecimento. O conceito de competência, amplamente difundido como o conjunto de conhecimentos, habilidades e atitudes, desenvolvido em uma determinada área, encontra ressonância tanto no espaço educacional quanto no terreno profissional e corporativo. Nesse sentido, salienta-se que não se trata, portanto, apenas de um "paradigma pedagógico" (ZABALA; ARNAU, 2010), mas representa uma ou várias propostas auxiliares para a compreensão do processo de formação de cada indivíduo em termos de aprendizagem ao longo da vida e desempenho competente de suas funções profissionais, bem como humanas e cidadãs.

Ao observar o movimento global das últimas décadas, com suas especializações e necessidades de conhecimentos tecnológicos, pode-se inferir que os estudos e aplicações sobre competências são frutos da complexidade imposta pela sociedade atual, promovendo o diálogo entre as ciências, as artes e as técnicas. Ou seja, o conceito de complexidade está relacionado à diversidade múltipla, respeitando-se a "tessitura comum" daquilo que é "tecido junto", portanto, o complexo que ela forma para além de suas partes. (MORIN, 1998). Dessa forma, observa-se que o conhecimento advindo das especializações disciplinares de certos domínios, desloca-se de forma interdisciplinar e não antagônica pelo emprego das competências.

Diante de tais prerrogativas, alicerçadas pelas exigências da sociedade atual, percebese que adquirir conhecimento e o domínio de algumas técnicas não são suficientes para saber agir de modo competente, para que esse conhecimento seja aplicado em situações reais do cotidiano de uma determinada área. Ao longo dos últimos anos, sob esse pensamento, a aplicação do conceito de competência se difundiu no contexto pedagógico nas diversas instâncias do ensino visando à formação integral do educando. (ZABALA; ARNAU, 2010).

Nesse sentido, o valor do conhecimento está ligado especialmente aos processos de apreensão do conteúdo por parte de cada estudante, mediante o uso de metodologias ativas, e como estes conduzem diferentes situações de aprendizagem durante a formação, para aplicálas nas ações cotidianas da atuação profissional. Mais especificamente, parte-se da hipótese de que cada indivíduo possui formas diferentes de gerir a própria formação no que tange às estratégias de aquisição do conhecimento, contextualização, perspectivas cognitivas e sociais, 
ênfase em fatos da vida cotidiana, formulação de conceitos, aplicação, pertinência, avaliação e transferência de informação.

As universidades, de modo geral, têm representado o ambiente propício à construção de complexas redes de aprendizagem mediante o emprego de competências, que ligam áreas e disciplinas, as mais variadas, na construção do conhecimento. Por outro lado, devido a essa complexidade, inerente ao saberes científicos e suas representações, se torna cada vez mais complexo conceber mecanismos capazes de estabelecer sistemas de informação, que tratem os diferentes tipos de conhecimento, identificando estruturas cognitivas e as relações conceituais existentes entre os sistemas de aprendizagem, conteúdos informacionais, aplicabilidade e os seus usuários.

A partir de mudanças nos projetos pedagógicos, muitas universidades têm adotado nos currículos de seus cursos propostas educativas baseadas em competências básicas e essenciais necessárias à formação de um determinado profissional. Essa ação visa sistematizar o grau de domínio de conhecimento e determinadas habilidades que devem ser adquiridas ao longo de uma formação acadêmica. Nesse sentido, fatores importantes são analisados e considerados, como por exemplo, o cenário em que se desenham as manifestações da sociedade e suas exigências, o ambiente de trabalho, o desenvolvimento das tecnologias e seus efeitos em determinada área e o público para quem se destina como é o caso da Saúde.

Mediante critérios estabelecidos para o ensino por competências nas universidades, a competência em informação representa um dos pré-requisitos fundamentais para a distinção do aluno. O que está, portanto, diretamente relacionado com os usos e meios que permitem ao educando acender a conteúdos necessários em uma pesquisa documentária para seu desempenho, a partir de estratégias metodológicas que possam ser evidenciadas em uma determinada situação de aprendizagem visando a solução de um problema informacional, de modo eficiente e eficaz.

Pelas especializações inerentes a cada área de conhecimento, os planos estratégicos para a definição das competências essenciais à formação de um grupo de profissionais são bastante específicos, inclusive no que tange à competência informacional. Dessa forma, esta pesquisa optou por desenvolver estudo sobre essa temática na área da Saúde, especificamente dos estudantes dos cursos de Medicina, Odontologia, Enfermagem e Farmácia da Universidade Federal do Ceará (UFC), usuários da Biblioteca de Ciências da Saúde (BCS/UFC). Visa compreender como esse público lida no cotidiano de sua formação com os 
processos de pesquisa utilizando-se das ferramentas tecnológicas disponíveis, mediante o uso do computador e da internet.

\section{Competência Informacional em Saúde: estudos e tendências}

A competência informacional, em termos de preocupação com a formação em pesquisa e uso das tecnologias de informação por parte dos profissionais, tem se destacado sobremaneira em vários países. Dentre esses, pode-se evidenciar o Canadá como referência na matéria, cujos resultados e modelos aplicados têm sido amplamente utilizados, inclusive no Brasil. Vários são os trabalhos produzidos por grupos de bibliotecários das universidades canadenses com o intuito de conhecer as necessidades informacionais daqueles que ingressam nessas instituições acadêmicas, bem como do nível de competência informacional desenvolvido por eles para o uso da informação mediada por computador. Como exemplo, pode ser citado o Étude sur les connaissances en recherche documentaire des étudiants entrant au ler cycle dans les universités québécoises, (2003), cuja pergunta de base para a construção do documento foi: quais são os conhecimentos essenciais para o sucesso de uma pesquisa documentária? O estudo foi desenvolvido utilizando-se a aplicação de questionário com mais de três mil estudantes das universidades de Québec, construído a partir das normas da Association of College and Research Libraries (ACRL, 2001), que dispõe sobre competências informacionais.

É também na América do Norte, mais especificamente nos Estados Unidos, que esses estudos se originaram e ganharam espaço no mundo inteiro a partir do conceito de information literacy, creditado a Paul Zurkowski, em 1974, que se insere na dimensão da cultura informacional, indo bem além da chamada formação de usuários para o acesso às fontes de informação, envolvendo compreensão, crítica, valor da informação, utilização, geração, exploração e comunicação do conhecimento em função da produção científica e das necessidades específicas de cada indivíduo em um determinado contexto colaborativo e dinâmico.

Muitas das universidades americanas, a partir de suas redes de bibliotecas, possuem programas de formação e de avaliação de competência informacional, amplamente estabelecidos e divulgados internacionalmente como é o caso da California State University (CSU), que integra uma rede de 23 campi universitários, assim como a University of California at Los Angeles (UCLA), cujo programa tem impacto na vida acadêmica em suas 
diferentes etapas, desde o ingresso dos estudantes em um curso superior percorrendo toda a vida acadêmica desses.

No âmbito da saúde, ainda no Canadá, verifica-se forte preocupação dos organismos públicos e privados com as possibilidades evidenciadas pela pesquisa documentária para o avanço das ciências médicas, de modo a assegurar a rápida evolução da qualidade dos conhecimentos clínicos e de fácil e competente acesso por parte dos seus profissionais mediante o uso das tecnologias de informação. O termo competência informacional na área da saúde é conhecido em sua versão inglesa como Health Literacy, com tradução para a língua francesa em Littératie (ou também littéracie) en Santé, continuamente empregado como Compétence Informationnelle en Santé (CIS).

O desenvolvimento da Competência Informacional em Saúde nos Estados Unidos e Canadá têm ocorrido por meio da formação de consórcios e redes entre bibliotecas universitárias, hospitais e centros médicos e de pesquisa, que levam em conta o fato de que a educação em saúde atualmente se dá em boa parte fora dos bancos das universidades mediante formação continuada, podendo ocorrer em diferentes lugares e situações mediadas e comunicadas pelo uso do computador. Essa constatação requer aptidões maiores dos usuários no manuseio das tecnologias informacionais para a realização de pesquisa documentária e o uso cada vez mais competente dos recursos disponíveis na internet como as bases de dados, os repositórios e demais instrumentos de pesquisa científica especializados em saúde.

As universidades brasileiras também são beneficiárias de excelentes e atualizados repertórios informacionais online em saúde, o que evidencia a necessidade cotidiana de formação competente dos profissionais para o uso desses mecanismos. Entretanto, as intervenções bibliotecárias dessas instituições, relativas ao desenvolvimento de programas, monitoramento e avaliação para a competência em informação ainda são incipientes ou não estão consolidadas. Alguns estudos localizados durante esta pesquisa demonstram que o que existe são pesquisas avaliativas e de constatação, realizadas na área de Ciência da Informação, especialmente em mestrados e doutorados, para mensurar a competência informacional de uma determinada área, baseadas em experiências internacionais, mas que não estão atreladas a programas consolidados de bibliotecas universitárias, na maioria das vezes. É importante destacar que os estudos de avaliação são fundamentais para a implantação de programas voltados para a competência em informação, mas que esses só se consolidam mediante 
políticas assumidas pelas instituições acadêmicas como um todo, pois dependem principalmente de recursos financeiros, pessoas e tecnologias.

As implicações teóricas e práticas deste estudo apontam para que a formação dos futuros profissionais em saúde, relativamente à competência informacional, almeje que o estudante seja capaz $\mathrm{de}^{2}$ :

- Evidenciar um problema de modo contextualizado e saber como localizar de forma competente a informação que leva a solucioná-lo de modo eficiente e eficaz;

- Saber avaliar de modo crítico a qualidade da informação localizada bem como de suas fontes;

- Saber como utilizar a informação obtida durante a pesquisa para a realização de seu trabalho;

- Saber desenvolver individualmente ou em grupo conhecimentos a partir da informação inicialmente localizada, contribuindo assim com o desenvolvimento da ciência;

- Compreender as questões culturais, éticas, legais e sociais relacionadas ao uso da informação obtida;

- Reconhecer a importância da aquisição de competências informacionais sob a perspectiva da formação continuada para o pleno desenvolvimento da profissão.

$\mathrm{Na}$ área da saúde, com relação ao seu contexto informacional e uso das tecnologias, há peculiaridades que a tornam bem específica, tendo em vista os aspectos éticos inerentes aos desafios de se lidar com seres humanos. Aprender a utilizar competentemente essas ferramentas informacionais, bem como os resultados delas advindos implica trabalhar dentro de uma lógica que envolve compartilhamento, trabalho cooperativo e dialogicidade. Nesse sentido, o papel da educação vai além do seu sentido tradicional relacionado ao ensino formal para uma prática de aprendizado contínuo, ainda no terreno da complexidade como discutido na introdução deste estudo.

Com efeito, a disposição para a aprendizagem em saúde situa-se no terreno da interdisciplinaridade, pois se trata de área cujos elos são bem próximos entre profissionais de várias disciplinas onde a mediação do conhecimento e a troca de experiências se dão mediante

\footnotetext{
${ }^{2}$ Baseado nas normas para os estudantes a partir do quadro de referência sobre competência informacional definido por (APRIL; BEAUDOIN, 2006, p. 175-176).
}

InCID: R. Ci. Inf. e Doc., Ribeirão Preto, v. 3, n.1, p. 87-104, jan./jun. 2012. 
trabalho conjunto que evidencia saberes teóricos e práticos nascidos das especializações, e alicerçado pelas tecnologias. Por conseguinte, o mediador interage com os demais sujeitos, que atuam e intervêm nas ações, articulando e reinventando em função da diversidade dessas ações desenvolvidas.

$\mathrm{Na}$ sociedade atual, todo o conhecimento se encontra interligado, vive-se em rede, no trabalho, na família, na escola, no lazer etc., em meio a conexões individuais e coletivas continuamente mediadas pelas tecnologias, que auxiliam na produção de sentido no cotidiano.

Assim, pode-se afirmar que o conhecimento é fruto das redes e o que se produz é o resultado das relações culturais e sociais entre os indivíduos, em determinada comunidade. Portanto, a sociabilidade e a sustentabilidade do conhecimento produzido no presente, para as gerações futuras, necessitam cada vez mais das competências humanas e de seus processos reflexivos, do diálogo, da troca de ideias e da integração para que se concretizem o direito à cidadania e o acesso democrático à informação, tanto no contexto local, quanto global da sociedade. (CAVALCANTE, FEITOSA, 2010, p.124)

A mediação científica se legitima pela produção de sentido, como por exemplo, aquela que ocorre nos espaços de transmissão de saberes, como as universidades a partir de grupos de pesquisa, laboratórios, salas de aula ou bibliotecas, com toda a sua diversidade.

Para Marteleto e Andalécio (2006, p. 4),

Mediação é uma construção teórica destinada a refletir sobre as práticas e os dispositivos que compõem os arranjos de sentidos e formas comunicacionais e informacionais nas sociedades atuais, sem perder de vista os elos que, tanto os conteúdos quanto os suportes e os acervos, mantêm com a tradição cultural.

No que concerne à pesquisa e aos usos competentes da informação em saúde, não dá para se estudar competência informacional sem discutir o conceito de mediação e a comunicação que se processa nos ambientes de ensino/aprendizagem. Dessa forma, essas considerações permeiam a prática cotidiana de disseminação da informação que ocorre nos ambientes acadêmicos mediados e comunicados por computador ou nas relações humanas diretas, que interferem no processo de construção coletiva do conhecimento.

De acordo com Raynauld et al. (2006), a competência é um saber-agir fundado a partir da mobilização e utilização de um conjunto de recursos (materiais, técnicos, humanos, éticos, etc.). Neste sentido, a aprendizagem em meio universitário deve ser contextualizada, integrada, mediada e transferível de modo a relacionar conhecimentos transversais e conceitos 
apreendidos durante o processo cognitivo individual de produção do conhecimento e de formação e de construção coletiva de um domínio.

Precisamente, com referência aos estudos de Raynauld et al. (2006), destacam-se categorias que auxiliam a pensar o objeto desta pesquisa:

Competências Transversais (CT): aprendizagens que operam nas experiências vividas, isto é no domínio geral de formação e que estabelecem uma relação entre a aprendizagem acadêmica e a vida cotidiana. Podem estar relacionadas ao sistema educação/formação, mas estão integradas às características individuais, atitudes e motivação pessoal, tradições sociais e culturais, traços de personalidade e conhecimento adquirido por canais informais. Competências Disciplinares $(C D)$ : se constitui mediante conhecimentos específicos apreendidos em uma dada disciplina e campos de atuação, o programa de formação, a linguagem utilizada e as formas de comunicação evidenciadas nos conteúdos e metodologias. Combina e mobiliza recursos, como por exemplo, das redes e associações profissionais, manuais de procedimentos, guias, estágios etc.

Além dessas duas categorias, a pesquisa também utiliza uma terceira categoria, as Competências Informacionais $(C I)$, para o entendimento relativo à importância dos sistemas de informação para a aprendizagem individual e coletiva. Esta última diretamente relacionada com o que se busca averiguar no que tange aos usos, pertinência, eficiência e eficácia da informação obtida em uma pesquisa científica mediada pelo computador.

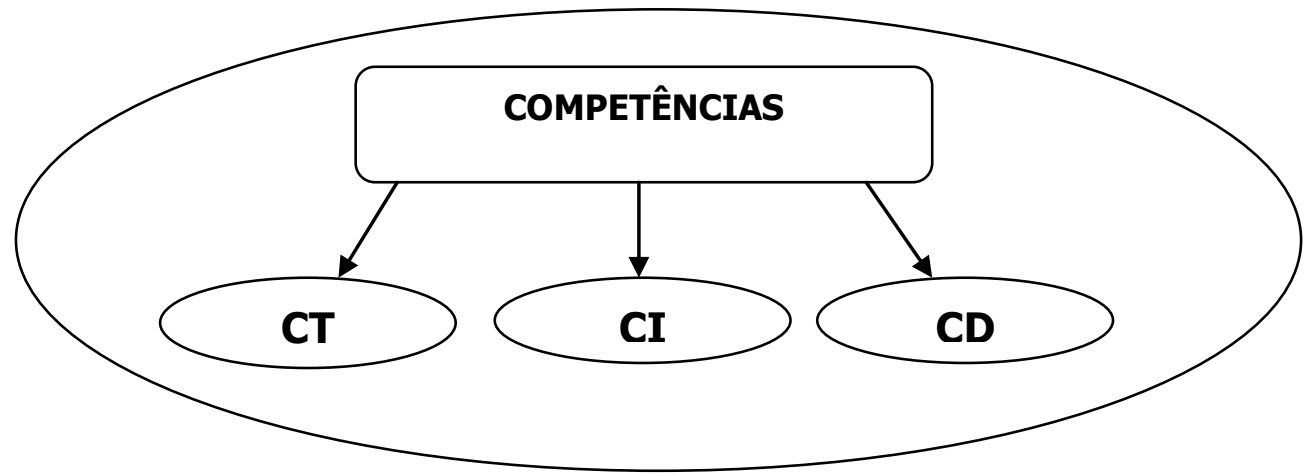

Figura 1 - Ciclo de aprendizagem baseado em competências

Esta figura representa as relações entre as especificidades do ciclo de aprendizagem constituído pelas Competências Transversais, as Competências Informacionais e as Competências Disciplinares, criado para esta pesquisa, que se manifestam no aprendizado ao longo da vida. Salienta-se, por conseguinte, que esse ciclo é permeado pela ação educativa em seus diferentes níveis, formal e informal - uma das condições fundamentais para o 
estabelecimento de vínculos entre o conhecimento advindo da cultura e das relações sociais e os novos conteúdos disciplinares e especializados inerentes a uma escolha profissional.

A competência advém de uma ação individual, mas também coletiva, pois além do compromisso pessoal, no âmbito profissional, uma ação competente resulta da junção de esforços e contribuição de outras pessoas.

Segundo Zabala e Arnau (2010, p. 96),

Para que o processo de aprendizagem seja desencadeado, não basta que os alunos se encontrem diante dos conteúdos para aprender, mas, antes, é necessário que eles possam atualizar seus esquemas de conhecimento, contrastá-los com o que é novo, identificar semelhanças e diferenças e integrá-las em seus esquemas, no entanto, isso nem sempre é possível. Dependerá, também, das capacidades cognitivas das quais os alunos dispõem para essa aprendizagem, ou seja, de nível de desenvolvimento. (grifo do autor).

Neste mesmo raciocínio, Primo (2001, p. 4) advoga que "É fundamental que, passada a névoa do deslumbre pela nova tecnologia, discuta-se não apenas as ferramentas que a informática oferece, mas que se pensem os métodos e as práticas educacionais." Ou seja, a educação também tem atravessado mudanças significativas, especialmente em seus processos de mediação, não mais centrados no conteúdo ou no professor, mas de valorização do aprendizado por parte do aluno e das formas desenvolvidas por ele de intervenção e inovação. "Logo, o conhecimento é construído interativamente entre o sujeito e o objeto. Na medida em que o sujeito age e sofre a ação do objeto, sua capacidade de conhecer se desenvolve, enquanto produz o próprio conhecimento.” (PRIMO, 2001, p. 4)

A competência em informação, portanto, está relacionada justamente ao potencial do indivíduo em romper com uma postura pacífica no recebimento de informações, sem dialogicidade ou interferência, mas em compreender como se dá as ações mediadoras que o levam a obter conhecimento de modo problematizador e cooperativo. "Enfim, a cooperação implica em respeito mútuo, reciprocidade, liberdade e autonomia dos interagentes." (PRIMO, 2001, p. 5).

Segundo Paquette (2005, p. 168), a identificação precisa da definição de competência a ser utilizada em um determinado estudo sobre essa temática permite representar graficamente os resultados e os integrar em um modelo de conhecimento. A Association of College and Research Libraries (ACRL) apresenta alguns princípios e indicadores de competência importantes para avaliar capacidades na utilização da informação. De acordo 
com esses princípios, apresentados por Stern (2002, p. 6), um indivíduo competente no uso da informação é capaz de:

Tomar consciência de sua necessidade de informação, encontrar a informação necessária, avaliar a qualidade de diferentes fontes de informação, utilizar eficazmente a informação em função de um objetivo dado, gerar informação de modo socialmente aceitável.

Essa conceituação está intrinsecamente relacionada à aprendizagem, portanto, a educação não tem como ignorar a importância dos estudos sobre competência informacional para o sucesso dos estudantes, independente do nível em que esses estejam. É óbvio que no ensino superior o uso dessas competências será mais exigido, o que torna ainda mais necessário o exercício desses conteúdos e metodologias nas etapas anteriores ao ensino formal. Nessa mesma direção, a International Federation of Library Association and Institutions (IFLA), afirma a importância do investimento em “[...] estratégias de competência informacional e do aprendizado ao longo da vida [para criar] valor público e é essencial ao desenvolvimento da Sociedade da Informação”.

É importante salientar também que,

As competências referem-se sempre às pessoas. Não existem competências sem indivíduos, sendo igualmente verdade que a competência não é unicamente um assunto individual. Toda a competência comporta duas dimensões indissociáveis: individual e colectiva. (CABRAL-CARDOSO; ESTÊVÃO; SILVA, 2006, p. 18)

O uso de sistemas educativos, ancorados por competências, também aproxima os estudantes da realidade profissional, pois se estabelece mediado pela cultura e o contexto nos quais estão inseridos (ANTONELLO, 2004). Nesse caso, a competência informacional obtém as condições necessárias para que a aprendizagem seja significativa, assim como os seus resultados.

\section{Estratégias Metodológicas}

A metodologia usada nesta pesquisa, além da revisão de literatura, é de natureza qualiquantitativa. Qualitativa, pois busca compreender percepções do grupo focal acerca do tema competência informacional em saúde e quantitativa por fazer uso de um instrumento estruturado de coleta de dados e de mensuração que é o questionário.

No âmbito teórico-metodológico deriva dos estudos realizados por Paquette (2005) sobre modelagem do conhecimento, competências e situações de aprendizagem, por meio de 
linguagens gráficas e representação por esquemas. De acordo com esse autor, gráficos e esquemas possuem papel primordial na construção do conhecimento, pois:

a) Guiam a percepção e auxiliam na construção de um processo ativo e seletivo;

b) São importantes instrumentos no processo de memorização e recordação;

c) Servem para a confrontação entre esquemas existentes e novos acontecimentos;

d) Auxiliam na resolução de tarefas complexas, na elaboração de planos e na identificação de objetivos.

A pesquisa foi realizada mediante estudo de caso aplicado na Biblioteca de Ciências da Saúde (BCS/UFC), tendo como critério de inclusão alunos dos cursos da área de saúde da referida universidade. Como já informado, utilizou-se como instrumento de coleta de dados um questionário, basicamente com vinte questões fechadas. A população foi determinada pela quantidade de alunos matriculados nos cursos atendidos pela BCS/UFC, sendo um total de 2.237 alunos.

A amostra foi calculada segundo a fórmula

$$
n=\frac{N p q Z_{\left(\frac{\alpha}{2}\right)^{2}}}{p q Z_{\left(\frac{\alpha}{2}\right)}{ }^{2}+(N-1) E^{2}}, \text { onde: }
$$

$\mathrm{n}$ = Número de indivíduos na amostra;

$\mathrm{N}$ = Tamanho da população;

$\mathrm{Z}_{\mathrm{a} / 2}=$ Valor crítico que corresponde ao grau de confiança desejado;

$\mathrm{p}=$ Proporção populacional de indivíduos que pertence a categoria em estudo;

$\mathrm{q}=$ Proporção populacional de indivíduos que NÃO pertence à categoria

em estudo $(\mathrm{q}=1-\mathrm{p})$;

$\mathrm{E}=$ Margem de erro.

$\mathrm{O}$ intervalo de confiança desejado foi de $95 \%$. Determinou-se um $\mathrm{Z}_{\mathrm{a} / 2}$ de 1,96 e tomou-se o valor $\mathrm{p}=0,8$ e, conseqüentemente, $\mathrm{q}=0,2$. A margem de erro imposta foi de $5 \%$. Assim sendo o cálculo amostral foi de $\mathrm{n}=222$ alunos. Foram entregues 315 questionários já se prevendo o número de instrumentos retornáveis, sendo que 150 foram devolvidos para análise, o que não invalida a pesquisa já que com esta amostragem foram feitos ajustes nos cálculos mudando-se o intervalo de confiança para $90 \%$. 
É importante mencionar que existem muitos instrumentos a serem aplicados para avaliação de competência informacional de um determinado grupo focal. Um dos mais utilizados, porém, é o questionário pela sua abrangência, retorno, garantia de anonimato e facilidade para se trabalhar com os dados coletados.

As questões foram organizadas em temas como apresentados a seguir:

- Conhecimento e habilidades no uso do computador;

- Conhecimento e habilidades em pesquisa bibliográfica e documentária;

- Estratégias de pesquisa e ferramentas utilizadas;

- Exploração dos resultados pesquisados.

A pesquisa foi desenvolvida de modo colaborativo entre pesquisador do Departamento de Ciências da Informação/UFC, profissionais da BCS/UFC e bolsistas que, juntos, determinaram a amostra, elaboraram o instrumento de coleta de dados, aplicação e análise dos resultados.

\section{Discussão e Resultados}

Os resultados obtidos com a pesquisa realizada com estudantes da área de saúde da UFC, após análise dos dados, levou a considerar que, entre outras questões, as quais serão discutidas a seguir, a preocupação com a competência informacional por parte dos alunos ainda é praticamente inexistente. A maioria solicitou explicação sobre o seu conceito, tendo em vista que nunca ouviu falar sobre o assunto. Talvez, isso se deva ao fato de que a BSC/UFC não tem ainda implementado, dentre suas ações, um programa de avaliação da competência informacional de seus usuários ou ações políticas e pedagógicas visando o desenvolvimento dessas.

Os resultados do estudo atestam que há entre ótima e boa familiaridade dos pesquisados em relação ao uso do computador e suas ferramentas disponíveis de trabalho como Word, Excel, Power Point, Internet Explorer, Compactadores de arquivos, e-mail etc. Percebe-se que a boa utilização dessas ferramentas está atrelada a necessidade de elaboração de trabalhos acadêmicos, que necessitam do uso da internet nas pesquisas bibliográficas para fundamentação desses trabalhos. Outro fato que justifica esse resultado é que são recursos presentes na vida acadêmica e cotidiana dos alunos para o bom desempenho de suas 
atividades escolares, comunicação entre colegas, professores, grupos de estudos, de pesquisa ou de trabalho.

As maiores dificuldades evidenciadas foram observadas em relação à realização de pesquisas bibliográfica e documentária. Apenas 6\% afirmaram ter ótimos conhecimento nesse quesito. Os 6\% que se declararam "ótimos" parecem ter a clarividência dos aspectos que envolvem a pesquisa, mas representa um índice muito baixo. Os 39,8 \% que se consideram "regulares", certamente não possuem competência informacional tão boa quanto deveriam, levando-se em consideração o fato de que se encontram em um ambiente acadêmico fortemente influenciado pelas tecnologias de informação, como a área da saúde. E os 44,2\% que se atestaram "bons", estão tentando desenvolver o hábito dessas pesquisas, mas não se pode avaliar aqui de que forma este aprendizado está sendo realizado, tendo em vista que a BSC/UFC não possui programa de avaliação dessas competências. O conhecimento em pesquisa bibliográfica e documentária, muitas vezes, se confunde com a ideia de simples acesso a internet, com o ato mecânico de levantar qualquer informação sem considerar critérios de seleção e qualidade que atestem seu valor científico. Há, portanto, certo equívoco entre ser letrado digitalmente e possuir competência informacional.

Especificamente no caso da saúde, isso se torna temerário tendo em vista os riscos que podem trazer consequências sérias aos seres humanos. Cita-se como exemplo, a pandemia de gripe de 2009, popularmente conhecida como gripe suína, que atingiu mais de 75 países e vários continentes. Os primeiros casos foram detectados no México, se espalhando por toda a América do Norte. Em pouquíssimo tempo uma avalanche de informação era veiculada na internet e em todos os meios de comunicação, o que gerou grande pânico na população do mundo todo. A Organização Mundial da Saúde (OMS) declarou que se tratava de uma emergência na saúde pública internacional, pois chegou a nível 6 de alerta, em uma escala de 1 a 6.

A gripe causada pelo vírus influenza A (H1N1) necessitou de uma junção hercúlea de profissionais e pesquisadores da área da saúde de todo o mundo para que o seu avanço fosse contido. "Passado apenas um mês da notificação do primeiro caso, já estavam disponíveis na literatura científica informações sobre o vírus, assim como a descrição de 642 casos da infecção com o vírus influenza A (H1N1) identificados nos Estados Unidos.” (MACHADO, 2009, p. 464). Em 2010 a pandemia já havia sido controlada graças à rapidez na realização das pesquisas científicas, a comunicação dos resultados e a eficiência na aplicação das 
medidas de combate e tomada de decisão das autoridades competentes. Em casos como esse, a credibilidade e a confiabilidade das fontes se tornam fundamentais para se evitar catástrofes maiores, diminuindo o número de possíveis vítimas para além dos casos fatais que foram noticiados e confirmados. Situações como essa que foi descrita advoga sobre a importância das fontes bem como a competência de quem as utiliza.

Em relação ao uso e conhecimento das bases de dados de pesquisa científicas, $70 \%$ dos pesquisados informaram serem insuficientes ou regulares seus conhecimentos sobre a BVS/BIREME ou Portal de Periódicos da Capes. Sobre o repositório SciELO, 38\% disseram ter bom conhecimento. Para $61 \%$ dos respondentes, seus conhecimentos em relação aos Descritores em Ciências da Saúde (DeCS) apresentaram resultado insuficiente. Em contrapartida, o Google, por exemplo, apresentou resultado ótimo, pois 95\% disseram ter conhecimento bom ou ótimo em relação a este site de busca.

Evidencia-se aqui a falha em boas práticas de pesquisa quando $70 \%$ declaram desconhecer o funcionamento dos principais portais direcionados ao pesquisador da área de saúde. A elaboração adequada de estratégias de pesquisas, para recuperação de informações relevantes, também fica comprometida quando $61 \%$ não sabem ou não compreendem a importância de uma terminologia controlada, no caso os Descritores em Ciências da Saúde (DeCS), criado pela BIREME.

Nesse sentido, o Sistema de Bibliotecas da UFC tem realizado ações intituladas Maratonas do Conhecimento, objetivando apresentar aos estudantes da instituição e a toda a comunidade acadêmica os mecanismos de busca de informação necessários à produção acadêmica no âmbito da pesquisa científica, com destaque para uso do Portal de Periódicos da Capes.

Ainda referente aos resultados da pesquisa, a facilidade no manejo de buscadores na Web, Google e Yahoo, eleva para 95\% as respostas favoráveis ao uso pleno desses recursos. As informações de sites governamentais, tais como ANVISA e Ministério da Saúde podem ser obtidas, e o são na maioria das vezes, através de buscadores como o Google. Isso faz com que o pesquisador deixe de acessar seus portais de origem em busca de conteúdos mais especializados. A Biblioteca Nacional e o Portal Domínio Público, como evidencia a pesquisa, sendo de caráter mais geral, não despertam tanto interesse dos usuários da área de saúde no desenvolvimento de seus trabalhos. 
Com relação ao uso de palavras-chave para se chegar à referência desejada observouse que $79 \%$ demonstraram ter esse conhecimento bem evidenciado. Entretanto, isso é bastante relativo, pois, o uso de termos livres em oposição às terminologias controladas pode resultar em menos relevância nos resultados das pesquisas. É necessário aprender a manejar as bases de dados e suas terminologias controladas para recuperar informações vitais ao desenvolvimento de uma determinada pesquisa. Para tanto, o ideal é conhecer os vocabulários definidos para cada base que se pretende usar, compreendendo como as palavras-chave que se quer empregar estão nelas representadas.

Foi perguntado aos respondentes como eles tomam conhecimento das revistas científicas, bases de dados, portais e bibliotecas virtuais na área da saúde para efetuar suas pesquisas. Para 55\%, os professores e/ou orientadores são as fontes mais confiáveis de informação, enquanto que $29 \%$ disseram tomar conhecimento das fontes de pesquisa mediante consulta ou conversas informais com colegas. $8 \%$ declararam que a internet os leva a tomar conhecimento das fontes de pesquisa. O que não se sabe é quais são os critérios adotados para selecionar as fontes confiáveis e de que maneira estão usando a internet, tendo em vista que a maioria das respostas sempre aponta para o uso pouco competente dos recursos e fontes científicas disponíveis.

Um dos maiores desafios da educação superior, como se pode observar, se refere às habilidades individuais e coletivas no uso da informação por parte dos estudantes, independente da área. Isto é, muitos entram e saem de um curso universitário com pouco ou nenhum conhecimento sobre competência no uso eficaz da informação para o desenvolvimento profissional ou mesmo têm consciência da sua importância. Em alguns casos, esse fator contribui para o abandono ou trancamento, número de anos no curso além da média, dificuldades de integração, descontentamento com a profissão que escolheu ou falta de oportunidades no mercado de trabalho.

$\mathrm{Na}$ área da saúde, essa situação é bem acentuada tendo em vista que o tempo excessivo na busca de informação para a solução de um problema pode significar a vida de um paciente ou mesmo atrasos em resultados de pesquisa, consideradas sempre muito longas nessa área. Por conseguinte, avaliar o comportamento informacional dos profissionais da saúde por parte dos bibliotecários, ainda no ambiente acadêmico é primordial para a implantação de programas visando o preenchimento das lacunas evidenciadas nesta pesquisa. 


\section{Conclusões}

Conforme as discussões desenvolvidas neste estudo, percebe-se que o movimento que ocorre para o desenvolvimento da competência informacional por parte das instituições de ensino superior, em âmbito nacional e internacional, com aporte das instituições bibliotecárias e da área da Ciência da Informação, se consolida como importante fator de sucesso para a sociedade. Isso ocorre tanto no campo profissional quanto em outras esferas da vida humana, por exemplo, social e cultural.

Por outro lado, ainda não parece claro para as instituições científicas, especialmente por parte dos pesquisadores, a exemplo da área da saúde, que não se trata apenas de mais um conceito ou modismo, que se limita a avaliação ou a identificação de falhas em sistemas de informação ou ações bibliotecárias. Trata-se de uma tendência contemporânea das mais complexas relacionadas ao crescimento das redes de informação e de suas vertentes educacionais e profissionais. Por conseguinte, há um reconhecimento internacional relativo à necessidade de que todas as áreas do conhecimento científico despertem para as relações interdependentes geradas nas especializações, mas que buscam a interdisciplinaridade. Nesse sentido, observa-se que as instituições acadêmicas, especialmente aquelas situadas em países desenvolvidos, realizam esforço coletivo de transformação das ações educacionais de maior valorização da informação e de suas formas de acesso, mediação e usos.

Esse processo de mudança na educação apresenta grandes desafios, pois não é fácil romper com estruturas engessadas de modelos tradicionais de ensino consolidados, como no caso da educação em saúde que envolve processos pedagógicos, conteúdos, formadores e alunos. Cabe, portanto, questionar a posição do profissional relativa à sua competência informacional no cotidiano de forma problematizadora para avaliar os impactos e evidenciar um problema de modo contextualizado e saber como localizar competentemente a informação que leva a solucioná-lo de modo eficiente e eficaz.

Estabelecer vínculos entre a Ciência da Informação e as demais áreas do conhecimento para o desenvolvimento conjunto de estudos, políticas e programas de competência informacional se torna fundamental para se vislumbrar possibilidades de intervenção e resultados satisfatórios. Especialmente, esses vínculos dependem do comprometimento de educadores e bibliotecários nos diferentes níveis da aprendizagem formal. 
Em matéria de formação documentária dos estudantes da área de saúde da UFC, além de se avaliar o nível de competência informacional, se faz necessário a implantação de programas de formação por parte da Biblioteca de Ciências da Saúde, bem como a conscientização de alunos e professores sobre a sua importância para o desempenho acadêmico e profissional, de modo a garantir à sociedade respostas rápidas para situações emergenciais. Nessa área, portanto, a preocupação com a competência informacional se torna fundamental tendo em vista que se trata de um campo sempre em alerta. Possibilidades de situações de riscos relativos à saúde pública, como no caso da gripe $\mathrm{A}$, causada pelo vírus influenza $(\mathrm{H} 1 \mathrm{~N} 1)$ podem ocorrer a qualquer momento, necessitando de tomada de decisões rápida e informações precisas. Lidar com as incertezas de dados informacionais pode tornar ainda mais difícil a solução para problemas emergenciais, bem como a intervenção a tempo de evitar catástrofes e pânico na sociedade.

Como se sabe, desenvolver qualquer tipo de ação em conjunto em universidades não se constitui matéria fácil. É tarefa das mais complexas, tendo em vista uma série de fatores como a quantidade de indivíduos e entidades envolvidos, a problemática de recursos e de pessoal, a dificuldade em aceitar mudanças que levem a deixar a "zona de conforto", o medo do insucesso, dificultando assumir riscos e desafios, entre outros. Um programa de competência informacional dificilmente poderá ser imposto, é necessária a compreensão dos envolvidos sobre a sua importância e o que isso representa como proposta de mudança profunda na aprendizagem e garantias para a sociedade.

\section{Referências}

ASSOCIATION OF COLLEGE AND RESEARCH LIBRARIES (ACRL). Information literacy competency standards for higher education. Chicago: ALA, 2001. Disponível em <http://www.ala.org/ala/arcl/arclstandards/standards.pdf>. Acesso em: 12 July 2011.

ANTONELLO, C. S. Alternativa de articulação entre programas de formação gerencial e as práticas de trabalho: uma contribuição no desenvolvimento de competências. 2004. 378 f. Tese (Doutorado) - Programa de Pós-Graduação em Administração, Universidade Federal do Rio Grande do Sul, Porto Alegre, 2004.

APRIL, J.; BEAUDOIN, M. Projet d'intégration des competences informationnelles: mise à l'essai d'un dispositive en enseignement préscolaire et primaire. Documentation et Bibliothèques, Montréal, v. 52, n. 3, p. 173-182, juil./sept. 2006. CABRAL-CARDOSO, C.; ESTÊVÃO, C.; SILVA, P. As competências transversais dos diplomados do ensino superior: perspectivas dos empregadores e dos diplomados. Minho: 
TecMinho, 2006. Disponível em: < http://www.citeve.net/bincache/XPQC1DD5C44796DF7273C88ZKU.pdf>. Acesso em: 13 ago. 2011.

CAVALCANTE, L. E.; FEITOSA, L. T. Bibliotecas comunitárias: mediações, sociabilidades e cidadania. Liinc em Revista, Rio de Janeiro, v. 7, n.1, p. 121-130, mar. 2001.

MACHADO, A. A. Infecção pelo vírus Influenza A (H1N1) de origem suína: como reconhecer, diagnosticar e prevenir. J. Bras. Pneumol., São Paulo, v. 35, n. 5, p. 464-469, 2009.

MARTELETO, R. M.; ANDALÉCIO, A. M. L. Jovens e violência: construção de informações nos processos de mediação e apropriação do conhecimento. In: ENCONTRO NACIONAL DE PESQUISA EM CIÊNCIA DA INFORMAÇÃO, 7., 2006, Marília. Anais ... São Paulo: UNESP, 2005. Disponível em:< http://www.portalppgci.marilia.unesp.br/enancib/viewabstract.php?id=301>. Acesso em: 22 jul. 2011.

MORIN, E. Complexidade e liberdade. São Paulo: [s.n.], 1998.

PAQUETTE, G. Modélisation des connaissances et des compétences: un langage graphique pour concevoir et apprendre. Quebec: Presses universitaires, 2005.

PRIMO, A. F. T. Ferramentas de interação em ambientes educacionais mediados por computador. Educação, v. 24, n. 44, p. 127-149, 2001. Disponível em:

<http://www.pesquisando.atravesda.net/ferramentas_interacao.pdf>. Acesso em: 13 set. 2011.

RAYNAULD, J. et al. Système de gestion de situations d'apprentissage et réforme d'enseignement au secondaire. Montreal: HEC, 2006.

STERN, C. M. La maîtrise de l'information « déconnectée: éduquer à l'information sans recourir aux tecnologies. [S.1.], 2002. Livre blanc préparé par l'UNESCO, a la U.S. National Comission on Libraries and Information Science et le National Forum on Inforation Literacy pour la Rencontre d'expercts sur la notion de competence informationnelle. Prague, République Tchèque. Disponível em: $<$ http://www.nclis.gov/libinter/infolitconf\&meet/sternfullpaper.html>. Acesso em: 10 nov. 2006.

ZABALA, A.; ARNAU, L. Como aprender e ensinar competências. Porto Alegre: Artmed, 2010.

Artigo submetido em: 27 mar. 2012

Artigo aceito em: 06 jun. 2012 